\title{
Retraction
}

\section{EpiPen: An R Package to Investigate Two-Locus Epistatic Models - RETRACTION}

\author{
Raymond K. Walters, Charles Laurin, and Gitta H. Lubke
}

doi:10.1017/thg.2014.25 Published online by Cambridge University Press 28 April 2014

Keywords: epistasis, SNP-SNP interactions, penetrance, variance explained, retraction

The paper 'EpiPen: An R Package to Investigate Two-Locus Epistatic Models' has been retracted at the authors' request in light of their decision to change the name of their research software to Epi2loc to avoid confusion with the EpiPen ${ }^{\circledR}$ Trademarks owned by Mylan Inc. The authors plan to republish the article under a different title in a forthcoming issue and apologise for any inconvenience caused.

\section{REFERENCE}

Walters, R.K., Laurin, C., \& Lubke, G.H. EpiPen: An R Package to Investigate Two-Locus Epistatic Models. Twin Research and Human Genetics, available on CJO2014. doi:10.1017/thg.2014.25. 